\title{
Systematic review on avian immune systems
}

\author{
Mastewal BIRHAN ${ }^{1 \ltimes 日}$ \\ College of Veterinary Medicine and Animal Science, Department Veterinary Paraclinical Studies, University of Gondar, Ethiopia \\ Corresponding author's Email: maste675@gmail.com; ORCID: 0000-0002-0984-5582
}

\section{ABSTRACT}

Aim. The aim of this review paper is too summarized and compares avian immune systems to the other domestic animals as comparative immunology type of review. Appreciation of the avian immune systems and their functions are very critical for disease diagnostics and new vaccine developments. Some of the avian immune systems are differ from mammalian immune systems, based on their production sources of immune cells like B-cells production site bursa of fabrics, but in mammalian is bone marrow. When we see the antibody type of birds; there are three principal classes of antibodies: IgM, IgG, IgY and IgA. Antibody diversity is achieved by gene re-arrangement. The other effector immune cell of birds is $T$ cells. There are two distinct pathways that are $\alpha / \beta$ and $\gamma / \delta$, avian T-cell diversity is probable made through combinatorial and junctional mechanisms. Recently, genes of several avian cytokines have been cloned and expressed. A number of naturally occurring viruses cause immunosuppression in chickens. Conclusion. There is much current interest in understanding the mechanisms of immunosuppression and developing strategies to enhance immune responsiveness in commercial poultry.

\author{
Review Article \\ PII: S225199391900023-9 \\ Rec. 06 June 2019 \\ Rev. 25 August 2019 \\ Pub. 25 September 2019 \\ Keywords \\ Antibody, \\ Avian, \\ T cells, \\ Vaccine
}

\section{INTRODUCTION}

One of the wonderful rules in the poultry industry is to hardly working on disease and predator control, good institutional linkage, and with good management from the healthy birds it is possible to increased high productive efficiency, capacity and with it, economic profitability" [1]. Scientific research on poultry immunology and the diseases affecting avian species is not a new concept [2]. But, more recently, the chicken was the first agricultural species as an income sources for which indicted by a genome sequence map [3]. Meaningful what specific immune molecules are encoded in the chicken genome delivers an outstanding background to form and magnify our information on the avian immune systems [2]. Comparable other avian immune systems, the immune system of chickens is made up of two types of mechanisms non-specific and specific [4]. The potential pathogen and other risks facing mechanisms are slight different from those come across by mammals. It is therefore essential that mechanisms be available to combat invading bacterial, viral and parasitic pathogens and to destroy neoplastic or other altered cells. It is also essential in birds, as in mammals, that the resulting immune response be regulated to ensure that it is adequate in quantity and quality $[5]$.

We need to understand the chicken immune system, to familiarize you with those defense mechanisms. The bursa of Fabricius and the thymus organs are the central lymphoid organs in the chicken, essential to the development of adaptive immunity [6]. In bird's poor of all bursal lymphoid tissue, but still holding a normal thymus, no circulating antibody was detected after challenge with different antigens. Delayed hypersensitivity reactions to tuberculin or vaccinia virus (VACV) were nearly completely inhibited [7].

From the pronounced important avian organs, gut-associated lymphoid tissue is one of the organ that contains functionally immature $\mathrm{T}$ and $\mathrm{B}$ lymphocytes at hatch, and that function is achieved during the first 2 weeks of age as demonstrated by mRNA expression of both ChIL-2 and ChIFN $\gamma$ confirmed by Bar-Shira et al. [8]. The gut is a vital organ system which makes up two equally important functions, that are digestion systems and host defiance [9]. When we address the chickens immune systems, the innate immunity includes physical barriers (skin, mucus coat of the GI tract), specific molecules (agglutinins, precipiacute phase proteins, lysozyme), phagocytic function of phagocytes (macrophages and neutrophils), and lysing activity of a class of lymphocytes called natural killer (NK) cells [10].

In females birds, may improve their reproductive victory by mediating brotherly competition and growth of offspring by means of differential hormone transfer to the egg yolk [11-13]. For example, differential transfer 
of steroids to eggs within the same grasp may alleviate or intensification the effect of hatching asynchrony as yolk steroids enhance nestling growth and competition [14] and [13]. Yolk testosterone was also present in the eggs of female canaries that were kept without a male, indicating that it is of maternal origin [11]. Birds are born with an imperfect immune system and young chicks have to rely on maternal antibodies and the innate immune defiance system to fight off pathogens [15].

While the avian system shares several similarities with mammalian systems, there are differences in the genes and molecules involved, the cells and organs involved, as well as the functional mechanisms. Chickens, for example, have a different assortment of Toll-like receptors, defensins, chemokines and antibodies. Birds do not have eosinophils though the functional corresponding to the mammalian neutrophil is the avian heterophil. Birds do not have lymph nodes, but do have a Bursa of Fabricius, which mammals do not. The mechanisms by which the different receptors are generated are also fundamentally different [16]. Therefore, the aim of this review paper are compering and analyzing of how the avian immune systems, structures organization, cells and organs differ from the other domestic animal immune systems.

\section{OVERVIEW OF THE AVIAN IMMUNE SYSTEMS}

Studies that comprehensive study type, as a comparative method to the immunology with an gratefulness for physiological ecology and evolution are defining an important new field in biology-ecological immunology [17]. Though in wide-ranging terms the avian immune response is strangely similar to that of mammals, when one looks at specifics birds have a different repertoire of immune organs, cells and molecules compared to those characterized in mammals.

The unique structures of chickens are adversely distresses by heat stress, so, due to this impressions reeducations of productive performance, immune response, survival and profitability of fast growing chickens [18]. Beyond the beneficial features, the risk regarding the development of antimicrobial resistance and transference of antibiotic resistance genes from animal to human microbiotaled the European Union to ban the application of antibiotics as growth promoters since ${ }^{\text {st }}$ January 2006, which was followed by the other parts of the world including North America [19].

Avian are extremely vulnerable to varies infection by opportunistic pathogens during the first few days after hatching [20]. In avian species, adaptive immunity encompasses both humoral and cell-mediated immune (CMI) responses [21]. The avian embryo provides numerous compensations for studies on development of the immune system [22]. The bird egg is worthily adapted to house, feed, and protect the developing embryo. The outer lime-flavored shell and adherent shell membranes provide a physical barrier that excludes most microorganisms, but permits free exchange of respiratory gases [23]. Interior to the shell membranes is a thick zone of albumen that provides a sterile fluid medium for the free growth and morphogenesis of the embryo and the extra embryonic membranes. In the center of the egg is the yolk mass that will nourish the embryo through the incubation period [24].

Commonly, Birds are lack organized lymph nodes, yet have the Bursa of Fabricius. Birds lack neutrophils and functional eosinophils, yet have a distinct group of polymorph nuclear granulocytes known as heterophil. Birds also have a different repertoire of cytokines, chemokines, Toll-like receptors, defensins and integrin's [25].

\section{INNATE IMMUNE SYSTEMS}

\section{Innate cells}

The innate immune system develops in the bone marrow (BM) from common myeloid progenitors (CMPs). Due to the expression of $A R$ in hematopoietic progenitors, there is reason to believe testosteronemay play an important role in shaping the immune cell repertoire even prior to the cells leaving the BM [26].

\section{Macrophages}

Macrophages instigate from bone marrow stem cells by differentiating into monoblasts, promonocytes, and monocytes. However monocytes establish foremost phagocytic cellular component in chicken blood, tissue macrophages are extensively dispersed and present in almost every organ. Monocyte cultures from peripheral blood leukocytes can be established by incubating the leukocyte fraction on a solid substrate such as Petri dishes or glass coverslips. The adherent blood monocyte cultures can then be established by incubation and washing off the non-adherent cell fractions [27]. The two most commonly used avian macrophages cell lines are 
MQ-NCSU. and HDil, an avian myelocytomatosis virus (MC29) transformed chicken macrophage-like cell line [28]. The MQ-NCSU cell line was established from spleen of a broiler-type chicken experimentally challenged with the JM/102W strain of Marek's disease virus. The cultural, morphological and functional characteristics of the MQ-NCSU cell line imply that this is a malignant-transformed chicken cell line belonging to the mononuclear phagocyte lineage. Avian macrophages harvest chemotactic cytokines of both macrophage inflammatory protein (MIP) families. The chicken MIP-1 and MIP-2 chemokines have the identical amino acid motifs as mammalian chemokines: adjacent cysteine's (CC) in the MIP-1 chemokines and cysteine's separated by another amino acid (CXC) in the MIP-2 family. The chicken MIP-2 family chemokine is currently designated as 9E3/CEF4. It has high homology to mammalian interleukin (IL)-8 and is abundantly expressed by activated peripheral blood monocytes [29-31].

\section{TLR}

Pattern recognition receptors (PRRs) are a serious component of pathogen recognition in both mammals and chickens [32]. Toll-like receptors (TLRs), a main family of PRRs, are expressed in chicken intestinal tissues and the local immune cells have been shown to respond to bacterial ligands [33]. Influxes of heterophil as well as increases in cytokines and chemokines are evident $[34,35]$ and are thought to contribute to the pathology detected. However, once chicks are more than a few days old, S. Typhimurium persistently colonizes their intestines in the absence of pathology [36], signifying that maturity of host defenses contribute to the deficiency of clinical signs

In chickens, it has been established that heterophil constitutively express TLR2A, TLR2B, TLR1/6/10 mRNA and that heterophil isolated from neonatal chicks and exposed to LTA undergo an oxidative burst [37]. There are also data to suggest that CD14 and TLR2 mediate LTA-stimulated oxidative burst in heterophil [37]. Chicken TLR3 expression pattern appears to be similar to what is observed in mammals [33]. For example, chicken heterophil express TLR3 and are approachable to poly I:C, demonstrated by an induced oxidative burst and degranulation of the stimulated heterophil, which may be mediated by a signalling pathway involving phospholipase $\mathrm{C}$, phosphatidylinositol 3-kinase and intracellular $\mathrm{Ca}^{2++}[38]$. In contrast, others have confirmed the poor ability of poly I:C to stimulate nitric oxide (NO) production in chicken monocytes, while HDilcells, a chicken macrophage cell line, were readily stimulated to produce NO by poly I:C [34,39].

The first groups of TLR are expressed on the cell surface and recognize primarily cell-surface PAMPs. They include TLR1, TLR2, TLR4-6 and TLR10 in human and TLR11 in mice. There are direct chicken orthologous of mammalian TLR4 and TLR5 [33, 40]. In mammals, there is a single TLR2 gene, and the genes encoding TLR1, 6 and 10 lie in a single locus. Mammalian TLR2 forms functional heterodimers with at least TLR1 and TLR6, allowing recognition of a wider panel of pathogen associated molecular patterns (PAMPs). At the equivalent locus to the mammalian TLR1, 6 and 10 locus, the chicken genome encodes only two genes, TLRILA and TLRILB [41, 42]. Avian TLR repertoire and the response to various agonists [43]. Toll-like receptors (TLRs) are important for eliciting innate immunity in animals by playing an essential role as pattern recognition receptors that detect infectious pathogens by recognizing the conserved molecular structures known as pathogen associated molecular patterns [44]. There are ten avian toll-like receptors and that five of these, TLR2a, 2b, 3, 4, 5 and 7, are clear orthologous to TLRs found in mammals [45]. The non-mammalian TLR21 exists in many species of birds, fishes, and frogs $[46,47]$. As a homologue of mammalian TLR9, TLR21 can recognize synthetic oligo-deoxy-ribonucleotides (ODN) and DNA viruses that contain CpG motifs, which further trigger the innate immune response [46, 48]. The RLR family encompasses three members: RIG-I, melanoma differentiation-associated gene 5 (MDA5) and research laboratory of genetics and physiology 2 (LGP2), which are located in the cytoplasm

\section{AVIAN ADAPTIVE IMMUNITY}

\section{Cell mediated immunity and humeral immunity}

Chicken $\alpha \beta$ T cells express either CD4 or CD8 accessory molecules, whereas most of the $\gamma \delta \mathrm{T}$ cells do not [49]. The cytotoxic $T$ lymphocyte response can decrease viral shedding in mildly pathogenic avian influenza viruses, but provides doubtful protection against HPAI. Influenza viruses can directly affect the immune response of infected birds, and the role of the Mx gene, interferon's, and other cytokines in protection from disease remains unknown [50]. Avian T cell progress has emerged with the use of monoclonal and functional antibodies to elucidate $\mathrm{T}$ cell differentiation antigens and molecular and functional explanations of mammalian 
$\mathrm{T}$ cell receptors (TCRs) [51]. Avian T cells bearing a $\gamma \delta \mathrm{TCR}$ are the first to be generated during ontogeny and they comprise up to $50 \%$ of the recirculating T-cell pool in mature birds [52].

Progress of B cells in chickens proceeds via a series of disconnected developmental phases that includes the maturation of committed B cell progenitors in the specialized microenvironment of the bursa of Fabricius [53]. Three classes of chicken immuno globulins have been identified immunochemically [54] and genetically [55] as homologues to the mammalian IgM, IgA and IgG, and their organizational properties have been reviewed in more detail elsewhere [56]. The intestine is a complex tissue that includes a major immune constituent. Indeed, the numbers of immune cells found in intestinal tissues exceed the numbers found in the rest of the body [57, 58].

Expression of selected genes involved in pathogen detection and the innate immune response were profiled in caecal tissues by quantitative RT- PCR. TLR4 and TLR21 gene expression was transiently increased in response to both bacterial species $[59,60]$ and. Defense of the intestinal mucosal surface from enteric pathogens is initially mediated by secretory IgA (SIgA) [61].

Three classes of chicken immunoglobulin's have been identified immunochemically $[62,63]$ and genetically $[64,65]$ as homologues to the mammalian IgM, IgA and IgG and their structural properties have been reviewed in more detail elsewhere [66]. Chicken IgM is structurally and functionally homologous to its mammalian counterpart, being current in serum as a high molecular weight pentamer of $\mathrm{m} 2 \mathrm{~L} 2$ units and being the first antibody generated during a primary antibody response. IgM is also the major class of immunoglobulin expressed on the surface of chicken B lymphocytes [67].

\section{Chemokines and Cytokines}

Interferon's (IFNs) are a family of multifunctional cytokines with significant roles in cellular resistance against viral infection [68]. In response to virus invasion, host pattern recognition receptors (PRRs) detect pathogen associated molecular patterns (PAMPs) and subsequent activation of innate immune system through retinoic acid inducible gene I (RIG-I) like receptors (RLRs)-MAVS-dependent IFN signaling or toll-like receptors (TLRs)-TRIF/MyD88-dependent IFN signaling [69], eventually, inducing the expression of type I IFNs. IFNs then bind their cognate receptors, triggering a signaling cascade that outcomes in the expression of abundant interferon-stimulated genes (ISGs) by the JAKSTAT signaling pathway, various of which possess antiviral properties [70,71]. Interferon regulatory factors (IRFs), a family of transcription factors, play authoritative roles in the regulation of IFN expression during viral infection [72]. To date, 9 IRF genes (IRF1-9) have been described in mammals, a tenth (IRF10) is present in numerous avian species and a total of 11 IRFs (IRF1- 11) have been identified in fish [68].

\section{CONCLUSION AND RECOMMENDATIONS}

The chicken, perhaps surprisingly, has made several influential contributions towards our understanding of immune responses as comparable way. Notwithstanding this, before the chicken genome sequence, our ability to study immune systems in detail in birds is appropriate and also in our thoughtful of the immune gene catalog. There are still gaps, both in the chicken immuno systems and their catalog. In comprehensive study is well important by comparing of birds immune systems with the other animals. Both innate and adaptive immune responses, with the latter including both cell-mediated and humoral immune responses, leading to address and increases our knowledge about chicken's immune activity. However, looking at the organs, cells, and molecules of the immune response in birds, it appears that mammals and birds accomplish the equivalent overall responses-often in quite different ways. Instead, we concentrate on the basic immune response, as well as a description of the major cell types and major areas where the cells and molecules of the immune response differ from those of mammals. Generally, the immune system of the chicken is very helpful in avoiding disease and helping to insure maxi-mum productive potential is realized. We must learn how to take advantage of all parts of the system when designing health programs. Based on the above information's the following recommendation will be forwarded:

$>$ Researcher should be focus on the avian immune systems and their role of contributions, and the delineation of the bursal and thymus-derived arms of the immune system.

$>$ The genes of several avian cytokines have been cloned and expressed; so that scientists would be given an attention for new disease resistant gene formed.

> The researcher should be emphasis on current attentiveness in thoughtful the mechanisms of immunosuppression and developing approaches to advance immune responsiveness in commercial poultry. 


\section{Acknowledgment}

The authors' heartfelt thanks to University of Gondar, research and community service v/president office, college Veterinary Medicine and Animal sciences for the financial and resource supporting

\section{Authors' contributions}

Mastewal Birhan conceived the review, coordinated the overall activity, and write and submit the manuscript.

\section{Availability of data and materials}

Data will be made available up on request of the primary author

\section{Consent to publish}

Not applicable.

\section{Competing interests}

The authors declare that they have no competing interests.

\section{REFERENCES}

1. Trenchi H. Immunology and disease prevention in poultry. Lohamann Inf. 2013; 48: 17-22. https://www.cabdirect.org/cabdirect/abstract/20133375514

2. Cheeseman JH. Avian immunology, immunogenetics, and host immune response to salmonella enterica serovar enteritidis infection in chickens. 2007. https://scholar.google.com/scholar?cluster=11576677371802678712\&hl=en\&as_sdt=2005\&sciodt=0,5

3. Wallis R, Broder M, Wong J, Hanson M and Beenhouwer D. Granulomatous infectious diseases associated with tumor necrosis factor antagonists. Clinical Infectious Diseases. 2004; 38 (9): 1261-1265. https://doi.org/10.1086/383317

4. Sharma J. Overview of the avian immune system. Veterinary immunology and immunopathology. $1991 ; 30$ (1): 13-17. https://doi.org/10.1016/0165-2427(91)90004-V

5. Sharma J and Tizard I. Avian cellular immune effector mechanisms-a review. Avian pathology. $1984 ; 13$ (3): $357-376$. https://doi.org/10.1080/03079458408418541

6. Cooper MD, Peterson RD, South MA and Good RA. The functions of the thymus system and the bursa system in the chicken. Journal of Experimental Medicine. 1966; 123 (1): 75-102. https://doi.org/10.1084/jem.123.1.75

7. Warner N, Szenberg A and Burnet FM. The immunological role of different lymphoid organs in the chicken: I. Dissociation of immunological responsiveness. Australian Journal of Experimental Biology and Medical Science. 1962; 40 (5): 373-388. https://doi.org/10.1038/icb.1962.42

8. Bar-Shira E, Sklan D and Friedman A. Establishment of immune competence in the avian galt during the immediate post-hatch period. Developmental \& Comparative Immunology. 2003; 27 (2): 147-157. https://doi.org/10.1016/Sol45305X(02)00076-9

9. Kiarie E, Romero LF and Nyachoti CM. The role of added feed enzymes in promoting gut health in swine and poultry. Nutrition research reviews. 2013; 26 (1): 71-88. https://doi.org/10.1017/S0954422413000048

10. Surai PF. Natural antioxidants in avian nutrition and reproduction. 2002. Nottingham University Press Nottingham;

11. Schwabl H. Yolk is a source of maternal testosterone for developing birds. Proceedings of the National Academy of Sciences. 1993; 90 (24): 11446-11450. https://doi.org/10.1073/pnas.90.24.11446

12. Wilson $\mathrm{CM}$ and McNabb FA. Maternal thyroid hormones in japanese quail eggs and their influence on embryonic development. General and comparative endocrinology. 1997; 107 (2): 153-165. https://doi.org/10.1006/gcen.1997.6906

13. Eising CM, Eikenaar C, Schwabl H and Groothuis TG. Maternal androgens in black-headed gull (larus ridibundus) eggs: Consequences for chick development. Proceedings of the Royal Society of London. Series B: Biological Sciences. 2001; 268 (1469): 839-846. https://doi.org/10.1098/rspb.2001.1594

14. Sockman KW and Schwabl H. Yolk androgens reduce offspring survival. Proceedings of the Royal Society of London. Series B: Biological Sciences. 2000; 267 (1451): 1451-1456. https://doi.org/10.1098/rspb.2000.1163

15. Sandell MI, Tobler M and Hasselquist D. Yolk androgens and the development of avian immunity: An experiment in jackdaws (corvus monedula). Journal of Experimental Biology. 2009; 212 (6): 815-822. https://doi.org/10.1242/jeb.022111

16. Jacob JP and Pescatore AJ. Barley $\beta$-glucan in poultry diets. Annals of translational medicine. 2014; 2 (2): $20-20$. 10.3978/j.issn.2305-5839.2014.01.02

17. Millet S, Bennett J, Lee KA, Hau M and Klasing KC. Quantifying and comparing constitutive immunity across avian species. Developmental \& Comparative Immunology. 2007; 31 (2): 188-201. https://doi.org/10.1016/j.dci.2006.05.013

18. Attia Y, Abd-El-Hamid A, ElKomy A and Shawky OM. Responses of productive, physiological and immunological traits of growing fayoumi males subjected to heat stress to vitamin c and/or e and organic zinc supplementation.

19. Sugiharto S. Role of nutraceuticals in gut health and growth performance of poultry. Journal of the Saudi Society of Agricultural Sciences. 2016; 15 (2): 99-111. https://doi.org/10.1016/j.jssas.2014.06.001

20. Lowenthal JW, Connick T, McWATERS PG and York JJ. Development of t cell immune responsiveness in the chicken. Immunology and cell biology. 1994; 72 (2): 115-122. https://doi.org/10.1038/icb.1994.18 
21. Erf G. Cell-mediated immunity in poultry. Poultry science. 2004; 83 (4): 580-590. https://doi.org/10.1093/ps/83.4.580

22. Fellah JS, Jaffredo T, Nagy N and Dunon D. Development of the avian immune system. Book title: Elsevier; 2014.p. 4563. https://doi.org/10.1016/B978-0-12-396965-1.00003-0

23. SETO F. Early development of the avian immune system. Poultry science. 1981; 60 (9): $1981-1995$. https://doi.org/10.3382/ps.0601981

24. Romanoff AL and Romanoff AJ. The avian egg. The avian egg. 1949.

25. Kaiser P. The avian immune genome-a glass half-full or half-empty? Cytogenetic and genome research. 2007 ; 117 (1-4): 221-230. https://doi.org/10.1159/000103183

26. Trigunaite A, Dimo J and Jørgensen TN. Suppressive effects of androgens on the immune system. Cellular immunology. 2015; 294 (2): 87-94. https://doi.org/10.1016/j.cellimm.2015.02.004

27. Qureshi M, Miller L, Lillehoj H and Ficken M. Establishment and characterization of a chicken mononuclear cell line. Veterinary immunology and immunopathology. 1990; 26 (3): 237-250. https://doi.org/10.1016/0165-2427(90)90094-9

28. Beug $H$, von Kirchbach A, Döderlein G, Conscience J-F and Graf T. Chicken hematopoietic cells transformed by seven strains of defective avian leukemia viruses display three distinct phenotypes of differentiation. Cell. 1979; 18 (2): 375390. https://doi.org/10.1016/0092-8674(79)90057-6

29. Bedard P-A, Alcorta D, Simmons DL, Luk K-C and Erikson R. Constitutive expression of a gene encoding a polypeptide homologous to biologically active human platelet protein in rous sarcoma virus-transformed fibroblasts. Proceedings of the National Academy of Sciences. 1987; 84 (19): 6715-6719. https://doi.org/10.1073/pnas.84.19.6715

30. Sugano S, Stoeckle MY and Hanafusa H. Transformation by rous sarcoma virus induces a novel gene with homology to a mitogenic platelet protein. Cell. 1987; 49 (3): 321-328. https://doi.org/10.1016/0092-8674(87)90284-4

31. Barker KA, Hampe A, Stoeckle $M$ and Hanafusa H. Transformation-associated cytokine 9e3/cef4 is chemotactic for chicken peripheral blood mononuclear cells. Journal of virology. 1993; 67 (6): $3528-3533$. https://doi.org/10.1128/jvi.67.6.3528-3533.1993

32. Klasing KC. Avian macrophages: Regulators of local and systemic immune responses. Poultry science. 1998; 77 (7): $983-$ 989. https://doi.org/10.1093/ps/77.7.983

33. Iqbal M, Philbin VJ and Smith AL. Expression patterns of chicken toll-like receptor mrna in tissues, immune cell subsets and cell lines. Veterinary immunology and immunopathology. 2005; $104 \quad$ (1-2): $117-127$. https://doi.org/10.1016/j.vetimm.2004.11.003

34. Henderson SC, Bounous DI and Lee MD. Early events in the pathogenesis of avian salmonellosis. Infection and immunity. 1999; 67 (7): 3580-3586. https://doi.org/10.1128/IAI.67.7.3580-3586.1999

35. Withanage G, Wigley $P$, Kaiser $P$, Mastroeni $P$, Brooks $H$, et al. Cytokine and chemokine responses associated with clearance of a primary salmonella enterica serovar typhimurium infection in the chicken and in protective immunity to rechallenge. Infection and immunity. 2005; 73 (8): 5173-5182. https://doi.org/10.1128/IAI.73.8.5173-5182.2005

36. Jones MA, Hulme SD, Barrow PA and Wigley P. The salmonella pathogenicity island 1 and salmonella pathogenicity island 2 type iii secretion systems play a major role in pathogenesis of systemic disease and gastrointestinal tract colonization of salmonella enterica serovar typhimurium in the chicken. Avian pathology. $2007 ; 36$ (3): $199-203$. https://doi.org/10.1080/03079450701264118

37. Farnell MB, Crippen TL, He H, Swaggerty CL and Kogut MH. Oxidative burst mediated by toll like receptors (tlr) and cd14 on avian heterophils stimulated with bacterial toll agonists. Developmental \& Comparative Immunology. 2003; 27 (5): 423-429. https://doi.org/10.1016/Sol45-305X(02)00115-5

38. Kogut $\mathrm{M}, \mathrm{He} \mathrm{H}$ and Kaiser P. Lipopolysaccharide binding protein/cdl4/tlr4-dependent recognition of salmonella lps induces the functional activation of chicken heterophils and up-regulation of pro-inflammatory cytokine and chemokine gene expression in these cells. Animal biotechnology. 2005; 16 (2): $165-181$. https://doi.org/10.1080/10495390500264896

39. Wu $\mathrm{Z}$ and Kaiser P. Antigen presenting cells in a non-mammalian model system, the chicken. Immunobiology. $2011 ; 216$ (11): 1177-1183. https://doi.org/10.1016/j.imbio.2011.05.012

40. Leveque G, Forgetta V, Morroll S, Smith AL, Bumstead N, et al. Allelic variation in tlr4 is linked to susceptibility to salmonella enterica serovar typhimurium infection in chickens. Infection and immunity. 2003; 71 (3): $1116-1124$. https://doi.org/10.1128/IAI.71.3.1116-1124.2003

41. Yilmaz A, Shen S, Adelson DL, Xavier S and Zhu JJ. Identification and sequence analysis of chicken toll-like receptors. Immunogenetics. 2005; 56 (10): 743-753. https://doi.org/10.1007/s00251-004-0740-8

42. Temperley ND, Berlin S, Paton IR, Griffin DK and Burt DW. Evolution of the chicken toll-like receptor gene family: A story of gene gain and gene loss. BMC genomics. 2008; 9 (1): 62. https://doi.org/10.1186/1471-2164-9-62

43. Boyd $\mathrm{A}$, Philbin V and Smith A. Conserved and distinct aspects of the avian toll-like receptor (tlr) system: Implications for transmission and control of bird-borne zoonoses. Secondary title: Portland Press Limited; 2007. https://doi.org/10.1042/BST0351504

44. Nang NT, Lee JS, Song BM, Kang YM, Kim HS, et al. Induction of inflammatory cytokines and toll-like receptors in chickens infected with avian h9n2 influenza virus. Veterinary Research. 2011; 42 (1): 64. https://doi.org/10.1186/12979716-42-64

45. Brownlie R and Allan B. Avian toll-like receptors. Cell and tissue research. 2011; 343 (1): $121-130$. https://doi.org/10.1007/s00441-010-1026-0 
46. Li Y-W, Luo X-C, Dan X-M, Qiao W, Huang X-Z, et al. Molecular cloning of orange-spotted grouper (epinephelus coioides) tlr21 and expression analysis post cryptocaryon irritans infection. Fish \& shellfish immunology. 2012; 32 (3): 476-481. https://doi.org/10.1016/j.fsi.2011.11.021

47. Wei L, Cui J, Song Y, Zhang S, Han F, et al. Duck mda5 functions in innate immunity against h5nı highly pathogenic avian influenza virus infections. Veterinary research. 2014; 45 (1): 66. https://doi.org/10.1186/1297-9716-45-66

48. Qi Y, Yan B, Chen S, Chen $\mathrm{H}$, Wang M, et al. Cpg oligodeoxynucleotide-specific goose tlr21 initiates an anti-viral immune response against ngvev but not aiv strain h9n2 infection. Immunobiology. 2016; 221 (3): 454-461. https://doi.org/10.1016/j.imbio.2015.11.005

49. ARSTILA TP, VAINIO $O$ and LASSILA O. Central role of cd4+t cells in avian immune response. Poultry science. $1994 ; 73$ (7): 1019-1026. https://doi.org/10.3382/ps.0731019

50. Suarez D and Schultz-Cherry S. Immunology of avian influenza virus: A review. Developmental \& Comparative Immunology. 2000; 24 (2-3): 269-283. https://doi.org/10.1016/S0145-305X(99)00078-6

51. Cooper MD, Chen C-LH, Bucy RP and Thompson CB. Avian t cell ontogeny. Book title: Elsevier; $1991 . p .87-117$. https://doi.org/10.1016/So065-2776(08)60823-8

52. Six A, Rast JP, McCormack WT, Dunon D, Courtois D, et al. Characterization of avian t-cell receptor $\gamma$ genes. Proceedings of the National Academy of Sciences. 1996; 93 (26): 15329-15334. https://doi.org/10.1073/pnas.93.26.15329

53. Masteller EL, Pharr GT, Funk PE and Thompson CB. Avian b cell development. International reviews of immunology. 1997; 15 (3-4): 185-206. https://doi.org/10.3109/08830189709068176

54. Dahan A, Reynaud C-A and Weill J-C. Nucleotide sequence of the constant region of a chicken $\mu$ heavy chain immonoglobulin mrna. Nucleic acids research. 1983; 11 (16): 5381-5389. https://doi.org/10.1093/nar/11.16.5381

55. Mansikka A. Chicken iga h chains. Implications concerning the evolution of $\mathrm{h}$ chain genes. The Journal of Immunology. 1992; 149 (3): 855-861.

56. Ratcliffe M. Chicken immunoglobulin isotypes and allotypes. HERZENBERG, LA et al. Handbook of experimental immunology. 1996; 5: 241-247.

57. Smith AL, Powers $C$ and Beal RK. The avian enteric immune system in health and disease. Book title: Elsevier; 2014.p. 227-250. https://doi.org/10.1016/B978-0-12-396965-1.00013-3

58. Ciriaco E, Píñera PP, Díaz-Esnal B and Laurà R. Age-related changes in the avian primary lymphoid organs (thymus and bursa of fabricius). Microscopy research and technique. 2003; 62 (6): 482-487. https://doi.org/10.1002/jemt.10416

59. Shaughnessy RG, Meade KG, Cahalane S, Allan B, Reiman C, et al. Innate immune gene expression differentiates the early avian intestinal response between salmonella and campylobacter. Veterinary immunology and immunopathology. 2009; 132 (2-4): 191-198. https://doi.org/10.1016/j.vetimm.2009.06.007

6o. Reimanb JJC and O'Farrellya C. Innate immune gene expression differentiates the early avian intestinal response 1 between salmonella and campylobacter 2. 2009.

61. Muir W, Bryden W and Husband A. Immunity, vaccination and the avian intestinal tract. Developmental \& Comparative Immunology. 2000; 24 (2-3): 325-342. https://doi.org/10.1016/S0145-305X(99)00081-6

62. Glbk B, Chang T and Jaap R. The bursa of fabricius and antibody production in the domestic fowl. Poultry Sci. 1956; 35: 224. https://doi.org/10.3382/ps.0350224

63. Ratcliffe M. Development of the avian b lymphocyte lineage. Critical reviews in poultry biology (USA). 1989.

64. Ratcliffe $M$ and Paramithiotis E. The end can justify the means. Secondary title; 1990. p. 217-226.

65. Pike KA and Ratcliffe MJ. Cell surface immunoglobulin receptors in b cell development. Secondary title: Elsevier; 2002. p. 351-358. https://doi.org/10.1016/S1044-5323(02)00068-4

66. Pike KA, Baig E and Ratcliffe MJ. The avian b-cell receptor complex: Distinct roles of ig $\alpha$ and ig $\beta$ in b-cell development. Immunological reviews. 2004; 197 (1): 10-25. https://doi.org/10.1111/j.0105-2896.2004.0111.x

67. Ratcliffe MJ. Antibodies, immunoglobulin genes and the bursa of fabricius in chicken $b$ cell development. Developmental \& Comparative Immunology. 2006; 30 (1-2): 101-118. https://doi.org/10.1016/j.dci.2005.06.018

68. Qian W, Wei X, Li Y, Guo K, Zou Z, et al. Duck interferon regulatory factor 1 acts as a positive regulator in duck innate antiviral response. Developmental \& Comparative Immunology. 2018; 78: 1-13. https://doi.org/10.1016/j.dci.2017.09.004

69. Gürtler C and Bowie AG. Innate immune detection of microbial nucleic acids. Trends in microbiology. 2013; 21 (8): 413420. https://doi.org/10.1016/j.tim.2013.04.004

70. Versteeg GA, Hale BG, van Boheemen S, Wolff T, Lenschow DJ, et al. Species-specific antagonism of host isgylation by the influenza b virus ns1 protein. Journal of virology. 2010; 84 (10): 5423-5430. https://doi.org/10.1128/JVI.02395-09

71. Versteeg GA and García-Sastre A. Viral tricks to grid-lock the type i interferon system. Current opinion in microbiology. 2010; 13 (4): 508-516. https://doi.org/10.1016/j.mib.2010.05.009

72. Negishi H, Osawa T, Ogami K, Ouyang X, Sakaguchi S, et al. A critical link between toll-like receptor 3 and type ii interferon signaling pathways in antiviral innate immunity. Proceedings of the National Academy of Sciences. 2008; 105 (51): 20446-20451. https://doi.org/10.1073/pnas.0810372105 